\title{
EDUCAÇÃO ESPECIAL NA PERSPECTIVA INCLUSIVA NO BRASIL: análise da influência internacional no contexto local
}

\author{
Adriana Araújo Pereira Borges \\ Universidade Federal de Minas Gerais - UFMG \\ Josiane Pereira Torres \\ Universidade Federal de Minas Gerais - UFMG
}

\begin{abstract}
Resumo
As Políticas de Educação Especial na Perspectiva da Educação Inclusiva fortaleceram-se a partir de uma agenda global, enfatizadas na década de 1990. No Brasil, essas políticas impactaram fortemente o sistema educacional. Nesse cenário, é possível detectar a influência de organismos internacionais, a partir dos conceitos de transferência e adoção de políticas públicas. Esse artigo discute como as orientações internacionais acerca da Educação Inclusiva foram adotadas no Brasil, a partir das propostas de formação docente para o trabalho junto aos alunos com deficiência e da formulação de políticas para o campo. Como resultado, é possível perceber que as Políticas de Educação Especial propostas pelos organismos internacionais encontraram terreno fértil no Brasil, pois o contexto local já possuía uma tradição na formulação e implementação dessas políticas realizadas em agendas internas. Pode-se perceber que, apesar da influência dos organismos internacionais, ocorreram transformações internas nas Políticas de Educação Especial no Brasil, favorecidas por comunidades epistêmicas e movimentos sociais locais.
\end{abstract}

Palavras chave: políticas de educação especial; organismos internacionais; comunidades epistêmicas, movimentos sociais

\begin{abstract}
Special Education Policies in the Inclusive Education Perspective were strengthened from a global agenda, emphasized in the 1990s. In Brazil, these policies strongly impacted the educational system. In this scenario, it is possible to detect the influence of international organizations, based on the concepts of transfer and adoption of public policies. This article discusses how international guidelines on Inclusive Education were adopted in Brazil, based on proposals for teacher training for working with students with disabilities and the formulation of policies for the countryside. As a result, it is possible to see that the Special Education Policies proposed by international organizations found fertile ground in Brazil, as the local context already had a tradition in the formulation and implementation of these policies carried out on internal agendas. It can be seen that, despite the influence of international organizations, there have been internal changes in Special Education Policies in Brazil, favored by epistemic communities and local social movements.
\end{abstract}

Keywords: special education policies; international organizations; epistemic communities, social movements 


\section{Introdução}

A inclusão de alunos com deficiência no sistema educacional gera, ainda hoje, muitas discussões. No Brasil, a criação do Instituto Benjamim Constant para cegos e do Instituto dos Surdos-Mudos (atual Instituto Nacional de Educação dos Surdos), no Rio de Janeiro nos anos 1854 e 1857, respectivamente, inauguram a possibilidade de educação para essas crianças. No entanto, é importante lembrar que essas iniciativas estavam restritas ao Rio de Janeiro. Ainda no final do século 19, classes anexas aos hospitais psiquiátricos foram estabelecidas, já que grande parte das crianças com deficiência permanecia institucionalizada nesses locais. Somente a partir do século 20, com a criação das classes especiais, o acesso de crianças às escolas é possível, se restringindo, no entanto, àquelas consideradas "escolarizáveis”. A partir da década de 1950, escolas especiais de cunho filantrópico são criadas em todo o território nacional, a partir da iniciativa de familiares de pessoas com deficiência (BORGES, 2018).

Em 1990, a Conferência Mundial de Educação Para Todos, realizada em Jomtien, na Tailândia, pode ser considerada um marco que inaugura uma nova agenda global. Organismos Internacionais, como a Organização das Nações Unidas (ONU), pretenderam responder às exigências de maior diversidade a partir do lema "Educação para equidade social” (OLIVEIRA, 2019). Em 1994, a Conferência Mundial de Educação Especial, realizada em Salamanca na Espanha, convocou os diferentes países a adotarem medidas que incluíssem os alunos com deficiência nos sistemas educacionais. A partir do paradigma da "Educação para Todos”, a perspectiva de Educação Inclusiva ganha força no cenário mundial, impulsionada pelas orientações dos Organismos Internacionais (OI’s). Além da ONU, outro organismo que tem influenciado cada vez mais os Sistemas Educacionais dos países e, consequentemente, as Políticas de Educação Especial e Inclusão é a Organização para Cooperação Econômica e o Desenvolvimento (OCDE).

O Brasil aderiu às orientações internacionais acerca da Educação Inclusiva de forma contundente, promovendo em um espaço de tempo relativamente curto, mudanças significativas que impactaram e continuam impactando o sistema educacional, tanto na educação básica quanto na educação superior. De acordo com os dados referentes à educação básica do ano de 2018, no Brasil foram realizadas um total de 1.181.276 matrículas de alunos Público-alvo da Educação Especial (PAEE) ${ }^{1}$ sendo que dessas, 1.014 .661 referiam-se a matrículas em classes do ensino comum (INEP, 2018). Ou seja, do total de alunos da Educação Especial no Brasil, no ano de 2018, 85,89\% estavam matriculados em escolas comuns. Os números no ensino superior acompanharam essa tendência de crescimento:

Em relação ao ensino universitário, dados do Censo da Educação Superior, de 2016, mostraram que 8.052.254 estudantes realizaram matrícula em IES no país, o que representou um crescimento de $62,8 \%$, frente a 2006, por exemplo. Em relação aos estudantes com deficiência o número que era de 5.395 em 2004, aumentou para 35.891 matrículas em 2016, o que representa um crescimento de aproximadamente 600\% (INEP, 2016). No entanto, esses dados ainda não consideram a recente implementação da Política que estabeleceu o sistema de 
cotas e o perfil do alunado que vem tendo acesso (VALLADÃO; ROCHA; BORGES, 2018).

Os dados demonstram que o Brasil implementou a Política de Educação Especial na Perspectiva da Educação Inclusiva (PNEEPEI) em seu Sistema Educacional, principalmente no que se refere ao acesso do aluno com deficiência à escola comum. Como consequência, o país criou uma vasta legislação sobre o tema. Mas é importante verificar em que medida as orientações internacionais, especialmente aquelas oriundas de Organismos Internacionais como a ONU e a OCDE, repercutiram na organização da PNEEPEI no país. Para isso, serão discutidas algumas orientações dos Organismos Internacionais, mais especificamente da ONU e da OCDE, a respeito da inclusão de alunos com deficiência na escola comum. Depois, serão analisadas as políticas de formação de professores para Educação Especial implementadas no Brasil a partir da década de 1990, focando tanto na legislação sobre a formação docente, quanto nos programas governamentais de incentivo para esses professores. Serão retomadas as noções de comunidades epistêmicas e de movimentos sociais, procurando revelar as circunstâncias que propiciaram a disseminação de inclusão educacional no Brasil. Por fim, os argumentos serão apresentados, bem como as considerações em relação as discussões elencadas no artigo.

\section{Políticas Educacionais Globais}

De acordo com Verger (2019), pesquisadores tem usado diferentes termos para se referirem à globalização da política educacional ou às políticas educacionais globais (PEG), como difusão, transferência, empréstimo, convergência ou políticas viajantes, dentre outros.

Atualmente, reformas educacionais semelhantes e um determinado jargão comum para referir as políticas de educação estão sendo aplicados em muitas partes do mundo, em locais incrivelmente diversos, tanto culturalmente como em termos de desenvolvimento econômico (VERGER, 2019, p.10).

Faria (2018) diferencia difusão e transferência de política, sendo que a transferência se concentra nos casos em que uma nação importa conhecimentos sobre políticas e programas, enquanto a difusão de políticas foca em como inovações, programas e políticas se espalham de uma entidade governamental para outra. Em relação às políticas de inclusão de alunos do PAEE em escolas comuns, o Brasil já possuía uma experiência na educação dessas crianças, mesmo que em escolas especiais, por isso é importante avaliar como se deu a transferência dessa política dos Organismos Internacionais para o Brasil, a fim de verificar o processo de adoção.

O momento de adoção é o outro lado da moeda da divulgação de políticas internacionais. Para que as políticas educacionais se tornem efetivamente globalizadas, elas precisam ser adotadas e institucionalizadas em redes de práticas 
por formuladores de políticas e profissionais. Muitas vezes, os países adotam políticas e programas educacionais globais porque são impostos externamente condicionados à ajuda ou pela coerção ou porque os estados-nação estão inclinados a aderir aos modelos mundiais de organização educacional (como a teoria da Sociedade Mundial assumiria). No entanto, os formuladores de políticas nacionais têm mais espaço para movimentar- se nos processos de reforma educacional do que algumas macroteorias preveem, e, muitas vezes, adotam as PEGs de forma voluntária. Assim, em um campo da política educacional globalizada, é mais relevante do que nunca compreender - e explorar empiricamente - por que os formuladores e políticas locais se envolvem com as PEGs, bem como quais são os processos, os motivos e as circunstâncias que favorecem a adoção da PEG (VERGER, 2019, p.18).

Ou seja, embora haja um movimento que pode ser mais ou menos coercitivo em termos de implementação de uma PEG, o contexto local adota a política a partir de suas próprias especificidades. No que diz respeito à política direcionada às pessoas com deficiência, veremos que, principalmente a ONU e a OCDE exerceram um papel importante, mas que somente essa influência não justificaria o alcance atingido no país por essa política.

\section{Orientações internacionais acerca da inclusão de alunos com deficiência: a agenda global}

É a partir da década de 1940 que a questão dos direitos das pessoas com deficiência entra, definitivamente, na agenda global. Em 1945, a criação da ONU no contexto de pósguerra reafirmou a importância da garantia de direitos para todas as pessoas. Essa organização intergovernamental, assume um papel importante a partir da realização de simpósios, conferências e da publicação de inúmeras resoluções que dizem respeito à pessoa com deficiência e seus direitos, envolvendo 193 Estados membros ${ }^{2}$.

De acordo com Faria (2018), pode-se reconhecer a existência de três tipos principais de organizações internacionais: as organizações intergovernamentais, as organizações não governamentais internacionais (ONGs internacionais) e as empresas multinacionais. As organizações intergoveramentais possuem secretariado permanente, incluem três ou mais Estados nacionais e são lastreadas por um acordo formal firmado entre os governos dos Estados nacionais. Em 1990, as organizações passam a se envolver ainda mais com as políticas sociais:

Primeiramente, vale recordarmos, a título de exemplo, a clara mudança na agenda das OIs durante a década de 1990, as quais, ao longo do período, se engajaram cada vez mais na seara das políticas sociais. A partir da produção e difusão de ideias e de modelos de políticas, bem como da oferta de financiamento e de "aconselhamento", elas se tornaram atores centrais nesse campo. Deacon e outros 
(1997) se referiram a esse processo como de "socialização da política global” e de globalização da política social nacional (FARIA, 2018, p.49).

Ainda de acordo com Faria (2018), a influência das organizações internacionais pode ser percebida em todo o Ciclo das Políticas: na definição da agenda, na formulação, implementação e avaliação da política. Dessa forma, essas organizações são geradoras e difusoras de ideias, multiplicando seu impacto e capilaridade.

Para Verger, "Atualmente, uma rede densa de OIs interage e compete para promover seus discursos educacionais e soluções de políticas preferenciais no campo da política educacional global” (VERGER, 2019, p.15). O poder desses organismos incide também sobre a capacidade de definir os principais problemas que os sistemas educacionais devem resolver, bem como as principais prioridades e objetivos da mudança educacional.

Nos anos 1990, os organismos internacionais incluem a educação em suas agendas, como, por exemplo, a Unesco, que realiza a Conferência Mundial Educação para Todos, em Jomtien, na Tailândia, e publica relatórios e documentos orientadores aos países signatários dos resultados da Conferência. Tais documentos são: A educação para todos (1990), A educação ao longo da vida (1993) e, ainda, Educação, um tesouro a descobrir (1996). Este último preconiza quatro pilares para a educação: aprender a conhecer, aprender a fazer, aprender a viver juntos e aprender a ser (PEREIRA, 2016).

Além da ONU, outro Organismo Internacional que têm influenciado países no que diz respeito às políticas educacionais é a Organização para Cooperação Econômica e o Desenvolvimento, criada oficialmente em 30 de setembro de 1961:

A Organização para Cooperação Econômica e o Desenvolvimento (OCDE) é um organismo internacional que tem por objetivo auxiliar os países-membros com estudos comparativos e análises internacionais sobre os temas que afetam o desenvolvimento econômico e social dos países ao redor do mundo (PEREIRA, 2016, p.54).

A OCDE legitima sua atuação ao unificar a teoria acadêmica com a conjuntura econômica dos países-membros, gerando recomendações políticas. Dessa forma, a OCDE instaura uma normatização e padrões de comportamento para os governos, condicionando o "bem-estar das pessoas" às exigências do mercado. Atua obtendo dados estatísticos, econômicos e sociais dos países-membros "em um processo regular de troca de informações, que gera as condições para que seus intelectuais os transformem em dados comparativos e indicadores sobre diversos temas”, dentre eles, a educação (PEREIRA, 2016, p. 56).

Desde sua criação, a OCDE teve a educação como pauta chave. E embora o Brasil não seja um Estado membro, é considerado colaborador, tendo uma relação próxima com esse Organismo Internacional. A partir de 2011, a OCDE tem organizado anualmente, Cúpulas Sobre a Profissão Docente. Para Almeida \& Viana (2019), os documentos que circulam a 
partir das cúpulas, assinalam a importância de procurar soluções para problemas apresentados como transversais aos sistemas educativos. Nessa perspectiva, os professores são apresentados como o fator que causa mais impacto na aprendizagem dos alunos. A intenção das cúpulas seria então, identificar linhas de atuação para a melhoria da qualidade do exercício profissional docente.

Uma das grandes questões sob a qual os participantes das cúpulas se debruçaram, foi a dificuldade em articular excelência, equidade e inclusão, a partir de um ensino de qualidade para todos. Embora essa temática estivesse presente em todas as cúpulas, a de 2014 trabalhou com mais afinco o tema. De acordo com o relatório final desse encontro (ASIA SOCIETY, 2014), uma das constatações foi o fato de países de contextos culturais diferentes enfrentarem desafios semelhantes em relação às dificuldades de conciliar excelência e equidade. A medida que a sociedade se modifica, há uma necessidade crescente de que as pessoas desenvolvam habilidades de nível mais alto, principalmente relacionadas ao uso das tecnologias. Como envolver pessoas com limitações motoras ou intelectuais no processo de aquisição de aprendizagens cada vez mais exigentes?

O desafio é criar condições de aprendizado para todas as crianças, independentemente de suas condições físicas, intelectuais, sensoriais ou mentais. As habilidades dos sujeitos com deficiência ou de comunidades vulneráveis não aparecem, não se evidenciam num mundo cada vez mais competitivo, com cobranças de resultados impossíveis para alguns sujeitos. Assim, excelência e equidade são frequentemente vistas como prioridades políticas concorrentes. No entanto, segundo o relatório de 2014, alguns países conseguem combinar altos níveis de desempenho dos alunos com uma distribuição equitativa das oportunidades de aprendizagem.

Outra pergunta colocada pelos participantes da cúpula foi: como atrair professores bem capacitados para atuarem em escolas de maior necessidade? Esse parece ser um desafio ainda sem solução. De acordo com as cúpulas, um dos pontos mais importantes em relação aos professores seria o compromisso de longo prazo com suas escolas, boas relações com as comunidades, e a capacidade de se envolver com os pais e influenciar as atitudes dos alunos em relação à sua educação. Ainda de acordo com o relatório de 2014, os sistemas educacionais precisam encontrar uma maneira de apoiar os professores nessas escolas para reduzir o atrito e promover a eficácia. Nessas escolas, a autoeficácia ${ }^{3}$ de professores e alunos está intimamente interligada. Para que os professores permaneçam e sejam eficazes em situações desafiadoras, eles precisam estar equipados com as habilidades necessárias para identificar alunos em dificuldades, entender as diferenças culturais e diagnosticar os alunos. Outro conceito importante abordado nas cúpulas foi o de aprendizagem ao longo da vida. Esse conceito já estava na pauta das OI’s desde a década de 1990, mas retorna com força nos últimos anos. De acordo com o Relatório para a Unesco: Educação, um tesouro a descobrir, de 1998:

Por todas estas razões, parece impor-se, cada vez mais, o conceito de educação ao longo de toda a vida, dadas as vantagens que oferece em matéria de flexibilidade, diversidade e acessibilidade no tempo e no espaço. É a ideia de educação 
permanente que deve ser repensada e ampliada. É que, além das necessárias adaptações relacionadas com as alterações da vida profissional, ela deve ser encarada como uma construção contínua da pessoa humana, os seus saberes e aptidões, da sua capacidade de discernir e agir. Deve levar cada um a tomar consciência de si próprio e do meio ambiente que o rodeia, e a desempenhar o papel social que lhe cabe enquanto trabalhador e cidadão (DELLORS et al, 1998, p.18)

Por fim, o relatório de 2014 afirma que práticas como repetição de série tendem a reduzir a equidade, enquanto a identificação precoce das dificuldades dos alunos e a provisão de suportes acadêmicos e sociais que mantêm os alunos acompanham o aumento da equidade.

Outro documento importante relacionado à educação de pessoas com deficiência foi publicado pelo Centro de Pesquisa e Inovação Educacional (CERI) da OCDE, intitulado: “Implementando a Educação Inclusiva. Procedimentos da OCDE”. Trata-se de um documento de 1997, que contém 25 trabalhos apresentados como parte de um projeto internacional de 7 anos (1990-1996) relacionado à "integração de crianças com necessidades educacionais especiais” (OCDE, 1997). De acordo com o documento:

Nos últimos 20 anos, houve muitas mudanças em nossa visão sobre a responsabilidade que a sociedade tem em relação às pessoas com deficiência, da maneira que esperamos que as pessoas com deficiência respondam à educação e na medida em que pensamos que eles podem e devem contribuir para a sociedade. Durante grande parte desse período, dentro da OCDE, o Centro de Pesquisa e Inovação Educacional (CERI) tem participado ativamente da pesquisa e da consideração de políticas nesse campo. Essas mudanças foram impulsionadas por movimentos de direitos civis, por preocupações humanitárias e por uma melhor compreensão baseada em pesquisa dos problemas educacionais enfrentados por pessoas com deficiências. Atualmente, existe uma crença generalizada de que é necessário desenvolver políticas para estimular a inclusão de crianças e adultos com deficiência nos sistemas educacionais. Além disso, agora é amplamente aceito que os que abandonam a escola e os adultos com deficiência devem ter melhor acesso ao mercado de trabalho. É amplamente reconhecido que as pessoas com deficiência têm muitas habilidades que poderiam, com suporte apropriado, ser usadas com muita eficácia no local de trabalho. O desenvolvimento acelerado em tecnologia é uma força adicional a essa convicção e um trabalho substancial está sendo realizado para identificar os tipos de apoio que as pessoas com deficiência precisam no trabalho para que possam contribuir em termos iguais com outros trabalhadores (OCDE, 1997, p.12, tradução nossa).

Importante perceber nessa passagem que a OCDE justifica a opção pela Educação Inclusiva pelo movimento dos direitos civis, preocupações humanitárias e uma melhor compreensão sobre as deficiências, baseada em pesquisas. Ou seja, a própria OCDE confirma a importância dos movimentos de conquista de direitos e de uma mudança da concepção da deficiência, que se inicia a partir dos anos 1960, com o modelo social. Para Madruga (2013), 
é possível pensar a deficiência a partir de três modelos distintos: o modelo de prescindência, em que predominava o viés religioso; o modelo médico, ou reabilitador, que visava a normalização; e o modelo social, que entende a deficiência a partir da interação de fatores médicos (referentes à deficiência) com os fatores sociais. O modelo social da deficiência é importante na medida em que quebra paradigmas. Mas ao mesmo tempo, o caráter "econômico" da OCDE se desvela: é preciso que as pessoas com deficiência sejam capacitadas para o trabalho. É certo que as pessoas têm esse direito e que ele é inquestionável. No entanto, não podemos ignorar o fato da OCDE ter afirmado que a colocação de crianças com deficiência em classes comuns ser de sete a nove vezes mais econômica do que colocálas em escolas especiais (WORLD BANK, 2003).

Portanto, a agenda global dos Organismos Internacionais elegeu a Educação como prioridade e a Educação Inclusiva (pelos aspectos aqui assinalados, como a questão da luta por direitos, a observação ao modelo social da deficiência, o avanço no conhecimento sobre as especificidades de aprendizagem desses sujeitos, ou por critérios econômicos) alcançou um status privilegiado na formulação de políticas públicas educacionais de vários países.

\section{Enfoque da Educação Especial na política nacional de formação de professores}

Ao analisar o percurso histórico da Educação Especial no Brasil nota-se uma série de tensões se materializando e, consequentemente, medidas políticas fizeram-se necessárias para garantir o que hoje dissemina-se como uma "perspectiva inclusiva" da Educação Especial.

Nesse cenário, a Constituição Federal brasileira (BRASIL, 1988) garante a obrigatoriedade de acesso à escolarização pública e gratuita no ensino regular e propõe o chamado Atendimento Educacional Especializado (AEE) em salas de Recursos Multifuncionais, sendo esse um tipo de serviço adotado como medida para ampliar as possibilidades de escolarização do aluno com deficiência. Dessa forma, o país busca atender em sua legislação as recomendações disseminadas mundialmente (UNESCO, 1990; 1994) de que as escolas precisam adequar-se para garantir o acesso para todos. Esse modelo de AEE começou a se popularizar em documentos oficiais até sua regulamentação (BRASIL, 2009; BRASIL, 2008). Há considerações de que o serviço de AEE configura-se com um perfil de "tamanho único" (MENDES, 2017) e que não tem sido acessado por todos os estudantes do PAEE. Como resultados das medidas empreendidas pelos Governos a partir da década de 1990, cujo enfoque foi garantir o acesso do aluno com deficiência na escola comum, os dados de matrículas divulgados pelo INEP (indicadores por meio dos quais é possível mensurar esse efeito) e que são amplamente disseminados pelo Ministério da Educação (MEC), evidenciam ano a ano, um significativo aumento no número de matrículas de alunos do PAEE nas escolas comuns.

Tais resultados são divulgados com entusiasmo anunciando o "sucesso", embora relativo, da política de inclusão escolar no Brasil. O aumento das matrículas indica que o 
estudante PAEE está tendo acesso ao ensino comum, no entanto, não é possível afirmar que o acesso à aprendizagem esteja garantido. Nesse sentido, dentre as tensões que se colocam como barreira para alcançar o sucesso desses estudantes, destacam-se as queixas do professor regente das diversas áreas do conhecimento do currículo da educação básica, diante da crescente demanda de matrículas de alunos do PAEE na escola comum. Tais queixas evidenciam a precariedade da formação dos profissionais em atender essa demanda, reflexo de uma escassa política de formação de professores no contexto da Educação Especial no Brasil. Diferentes documentos internacionais afirmam que a "preparação apropriada de todos os educadores constitui-se um fator chave na promoção de progresso no sentido do estabelecimento de escolas inclusivas” (UNESCO, 1994, s/p).

Conforme discutido, existe um esforço do Brasil em acompanhar as recomendações de Organismos Internacionais em garantir o acesso à escola por todos sem distinções, e parte desse esforço é fator que contribuiu para a constituição da Educação Especial como uma política pública e o fortalecimento da perspectiva da inclusão escolar no país. No entanto, para o campo da Educação Especial, esse esforço ainda não tem sido refletido com estima merecida nas políticas de formação de professores.

A Lei de Diretrizes e Bases da Educação Nacional (BRASIL, 1996) no Art. 59 dedicado à Educação Especial, incube aos sistemas de ensino que seja assegurado professores para o atendimento especializado aos estudantes do PAEE, os quais deverão possuir especialização adequada, seja em nível médio ou superior, comprometendo-se ainda a capacitar os professores para a inclusão desses estudantes nas classes comuns.

A Resolução $n^{0} 2$ de 2001 (BRASIL, 2001a) retoma esses dois profissionais apresentados pela LDB, definindo os professores capacitados como os que possuem possibilidade de atuar com os estudantes do PAEE e que em sua formação, em nível médio ou superior, tenham sido incluídos conteúdos sobre a Educação Especial de forma que esses profissionais desenvolvam habilidades necessárias para atuar com esse público. Já os professores especializados são aqueles que podem comprovar formação em cursos de licenciatura na área, ou pós-graduação, ou complementação de estudos em áreas específicas da Educação Especial. E é previsto, ainda, para aqueles que já se encontram lecionando, a oportunidade de formação continuada, que pode ocorrer com a especialização. Dessa forma, a política de Educação Especial prevê dois profissionais que estariam aptos para lidar com estudantes do PAEE, cada um deles com perfis e formações específicas. Nesse sentido, cabe analisar por meio de documentos oficiais como tem sido orientado e sistematizado politicamente o perfil dos professores ditos capacitados e especializados.

No que diz respeito aos professores especializados, houve uma preocupação em determinar medidas que garantissem a formação desses profissionais, intensificadas com a implementação do Programa de Implantação de Salas de Recursos Multifuncionais (BRASIL, 2007a), definidas como lócus do Atendimento Educacional Especializado. O AEE começou a se estabelecer com maior força na política de Educação Especial, desencadeando o surgimento de uma série de programas (KASSAR, 2014; CARAMORI; MENDES; PICHARILLO, 2018). 
Em 2008 é publicada a Política Nacional de Educação Especial na perspectiva da Educação Inclusiva (BRASIL, 2008), que consolida a proposta do serviço de AEE e reforça a premência da formação do professor para atuar na Sala de Recursos. E ainda, que os professores aptos a atuar na Educação Especial teriam "como base da sua formação, inicial e continuada, conhecimentos gerais para o exercício da docência e conhecimentos específicos da área” (BRASIL, 2008, p. 13). Dessa forma, nota-se certa expectativa para o estabelecimento de um perfil de profissional capaz de lidar com as atividades típicas da docência, e ainda, conhecer e saber atuar com as especificidades provenientes das deficiências, previsão já apontada na LDB em 1996.

Bueno (1999) afirma que a formação de professores de Educação Especial foi elevada ao nível superior com a publicação do Parecer n²95/69, e por um período, a Educação Especial foi considerada como uma habilitação específica inserida em cursos de Pedagogia, prática extinta a partir da publicação da Resolução CNE/CP n ${ }^{\circ}$ 1, de 15 de maio de 2006 (BRASIL, 2006a). Atualmente no país, existem dois cursos de formação de professores de Educação Especial em nível superior ofertados em universidades públicas da região Sul e Sudeste do Brasil, além de outros ofertados em universidades privadas. Segundo Caramori; Mendes; Picharillo (2018) a abertura da maior parte desses cursos pode ter sido uma medida para responder a demanda advinda da política de inclusão escolar e como providência às lacunas deixadas pela extinção da Educação Especial como habilitação nos cursos de Pedagogia.

Uma pesquisa desenvolvida em rede com os estados brasileiros buscou, dentre outros objetivos, diagnosticar a formação do professor que atua em salas de Recursos Multifuncionais (MENDES et al., 2015), ou seja, os definidos na política como professores especialistas. Dada a amplitude e alcance (19 estados brasileiros), a pesquisa citada possibilitou traçar um panorama da realidade da implementação da política de inclusão escolar disseminada no país. No que diz respeito a formação dos professores especialistas, os resultados apontaram que o perfil de formação inicial desses professores tem prevalência em cursos de Pedagogia, e segundo os próprios professores, o sentimento é de que a formação recebida não fornece subsídios necessários para a efetiva atuação nesse serviço. Quanto à formação continuada, a maioria dos professores participantes do estudo indicou ter participado de cursos de especialização em Educação Especial e áreas afins. Inclusive, é reportada a presença de programas de formação continuada ofertados tanto pelo MEC, quanto pelas Secretarias Municipais de Ensino, embora os professores participantes da pesquisa que participaram de tais formações, tenham relatado insatisfação quanto ao modelo proposto.

Dado o exposto, foi caracterizado o perfil do professor especialista, ou seja, aquele que atua na Educação Especial por meio do serviço na Sala de Recursos Multifuncionais, na oferta do atendimento educacional especializado, adotado pela política de Educação Especial. Mas essa mesma política preconiza que o aluno PAEE deve frequentar regularmente a classe comum e que sejam supridas suas demandas de escolarização, visto que o AEE não substitui a escolarização formal e ocorre no contraturno. Na classe comum, o responsável é o professor regente da classe, que deveria ser capacitado para a função. 
A formação dos professores ditos capacitados, é regulamentada no Brasil pelas Diretrizes Curriculares Nacionais para a Formação de Professores da Educação Básica, em nível superior, em cursos de licenciatura, de graduação plena (BRASIL, 2001c). O art. 6 das Diretrizes menciona que na constituição dos projetos pedagógicos dos cursos de formação de professores, deve constar "II - conhecimentos sobre crianças, adolescentes, jovens e adultos, aí incluídas as especificidades dos alunos com necessidades educacionais especiais e as das comunidades indígenas” (BRASIL, 2001c, art. 6, § $3^{\circ}$ ). Anos depois, as novas Diretrizes (BRASIL, 2015) consideraram que o egresso de cursos de formação inicial em nível superior deveria estar apto, entre outros elementos a:

demonstrar consciência da diversidade, respeitando as diferenças de natureza ambiental-ecológica, étnico-racial, de gêneros, de faixas geracionais, de classes sociais, religiosas, de necessidades especiais, de diversidade sexual, entre outras (BRASIL, 2015, s/p).

Recentemente, foram publicadas por meio da Resolução CNE/CP n ${ }^{0} 2$ (BRASIL, 2019) as novas e atuais Diretrizes Curriculares Nacionais para a Formação Inicial de Professores para a Educação Básica, que institui a Base Nacional Comum para a Formação Inicial de Professores da Educação Básica (BNC-Formação). Para a área de Educação Especial, podese considerar que o documento integraliza mais esse campo do conhecimento em comparação com as duas diretrizes anteriores.

É proposto que os cursos de licenciatura sejam organizados em três grupos com carga horária e propósitos próprios, nos quais encontram-se os conhecimentos de base comum, conhecimentos específicos da área e as horas de prática pedagógica. A Educação Especial encontra-se prevista como componente de base comum com carga horária de 800 horas, sendo prevista a discussão dos "marcos legais, conhecimentos e conceitos básicos da Educação Especial, das propostas e projetos para o atendimento dos estudantes com deficiência e necessidades especiais” (BRASIL, 2019, Art. 12).

São apresentadas ainda pelas Diretrizes, no formato de anexo, habilidades esperadas para a formação docente, dentre elas destacam-se aquelas que contemplam direta ou indiretamente os alunos do PAEE. Nota-se um discurso em torno de considerar a heterogeneidade da sala de aula compreendendo o estudante com suas próprias individualidades, o que leva a perfis de aprendizagem diversos, características já reportadas na literatura científica (GIROTO; POKER; OMOTE, 2012). Nessa direção, as especificidades oriundas das deficiências são consideradas e há previsões de habilidades para o professor para atender as individualidades dos alunos, por exemplo, por meio do uso de estratégias de ensino que considerem as individualidades das deficiências, bem como a utilização de comunicação e práticas que garantam o entendimento de todos.

O que se nota na política é que, constantemente, ocorre uma ampliação das exigências para execução da prática docente, estabelecidas como habilidades e competências almejadas para esse profissional, no entanto, há pouca ou nenhuma contrapartida no que diz respeito à formação oferecida. E a literatura da área tem reportado que, no que diz respeito à formação 
inicial das licenciaturas, a Educação Especial não tem sido contemplada de forma a capacitar os futuros professores (PLETSCH, 2009), embora haja um consenso de que o possível sucesso de escolas com perspectiva inclusiva deve-se a uma adequada formação dos professores (UNESCO, 1994).

A tendência das políticas educacionais gerais e as específicas de Educação Especial no Brasil, tem sido priorizar a formação de professores que atuam na educação básica no modelo de formação continuada e/ou em serviço, e em muitos casos na modalidade da Educação à Distância (EaD). Nesse contexto, considera-se destacar o "Programa Educação Inclusiva: direito à diversidade” (BRASIL, 2006b) que teve como propósito formar gestores e educadores "para transformar os sistemas educacionais em sistemas educacionais inclusivos” por meio da oferta de cursos de formação continuada a esses profissionais.

Dentre as estratégias apresentadas na Meta 4 do atual Plano Nacional de Educação (PNE) encontra-se entre as prioridades para a área, "formação continuada de professores e professoras para o atendimento educacional especializado nas escolas urbanas, do campo, indígenas e de comunidades quilombolas” (BRASIL, 2014). No que diz respeito ao apoio técnico e financeiro nota-se maior ênfase em viabilizar a formação continuada de professores que atuam na modalidade da Educação Especial (BRASIL, 2011; 2007b) em detrimento à formação inicial. Nesse contexto, percebe-se certa adesão do Brasil, no que concerne à elaboração de suas políticas educacionais relacionadas à educação especial, às orientações de organismos internacionais, como por exemplo, no documento intitulado "Professores são importantes: atraindo, desenvolvendo e retendo professores eficazes”. Esse documento traz como objetivo "fornecer aos formuladores de políticas informações e análises para auxiliar na elaboração e na implementação de políticas para professores que resultem em ensino e aprendizagem de qualidade no nível da escola” (OCDE, 2006, p. 235), enfatizando que dentre as orientações para elaboração de políticas educacionais há de se considerar que "a educação inicial do professor deve ser concebida como a base para a aprendizagem continuada, e não como uma forma de produzir profissionais prontos” (OCDE, 2006, p. 140).

Sem desmerecer a importância da formação continuada, nossa preocupação é que apesar de todas as pesquisas que, há mais de duas décadas, vêm mostrando que os professores não estão preparados para lidar com a diversidade que se manifesta em turmas de alunos inevitavelmente heterogêneas, nossos cursos de formação, de modo geral, pouco se modificaram (CRUZ; GLAT, 2014, p. 259).

A inserção de uma disciplina em cursos de licenciatura promove discussões no sentido de questionar qual melhor abordagem em termos de conteúdo para promover o efeito almejado, isso porque, ainda "não há clareza de como deve ser essa formação no que diz respeito ao conteúdo e às abordagens” (TORRES; MENDES, 2019). No entanto, não há consenso entre os próprios pesquisadores do campo de conhecimento da Educação Especial de quais conteúdos priorizar quando se formula a ementa de uma disciplina com esses propósitos. Há de se considerar uma formação que ultrapasse a perspectiva restrita ou 
tecnicista, na qual apenas se enfoca em deficiências e suas respectivas características, dificuldades e práticas como receitas determinadas.

\section{Educação Inclusiva no contexto local: o papel das comunidades epistêmicas e dos movimentos sociais}

Nessa seção, será discutido o conceito de adoção, ou seja, os processos, motivos e circunstâncias que favoreceram a adoção da Política de Educação Inclusiva proposta na agenda global no contexto local, a partir da noção de comunidades epistêmicas e movimentos sociais.

Mendes, Almeida e Cabral (2018), afirmam que apesar do esforço dos Organismos Internacionais para atender as necessidades das pessoas com deficiência e viabilizar sua escolarização nos vários níveis de ensino, são diversas as interpretações e traduções das políticas e práticas nos diversos contextos educacionais:

Atualmente, temos que, em alguns países, o ensino voltado aos estudantes com deficiência ocorre somente em estabelecimentos especializados (como é o caso da Irlanda), ou predominantemente em classes comuns da rede regular de ensino (assim como ocorre na Itália), ou ainda sob a forma de continuum de serviços, com o estabelecimento de parceria entre a rede regular de ensino e as instituições especializadas (como é o caso predominante no Brasil) (MENDES, ALMEIDA; CABRAL, 2018, p.9).

Outro aspecto que muda de país para país é a definição do público da Educação Especial na Perspectiva Inclusiva. A legislação brasileira considera que o PAEE, ou seja, o público que se beneficia de serviços especializados, é formado por pessoas com deficiência, transtornos globais do desenvolvimento e altas habilidades/superdotação. Problemas comportamentais, transtornos que impactam a aprendizagem como a dislexia e o transtorno do déficit de atenção e hiperatividade, são beneficiados pela política de Educação Inclusiva, tendo direitos assegurados, como tempo maior para prova e atenção especial às especificidades. Mas atendimentos em Salas de Recursos Multifuncionais e adaptações curriculares mais específicas, são prioridade do PAEE.

Até a década de 1980 no Brasil, não havia separação entre alunos com deficiência e aqueles com problemas comportamentais e transtornos específicos de aprendizagem. Com tempo, ficou evidenciado que os alunos sem deficiência acabavam estigmatizados, principalmente aqueles alunos vulneráveis socialmente. Diferentes países definem de formas distintas, quais alunos podem ou não se beneficiar das políticas.

A configuração da Educação Inclusiva no Brasil na atualidade tem suas raízes nas primeiras iniciativas que se organizaram no país a partir do século 20, em diferentes estados. No Rio Grande do Sul, em Canoas, no ano de 1929, Tiago Wurth inaugurou o Instituto Pestalozzi, uma escola especial para crianças com deficiência. Em Pernambuco, Ulysses 
Pernambucano iniciou um trabalho pioneiro em 1925, ao criar a primeira escola especial no estado (BARRETO, 1992). Enquanto isso, em Minas Gerais, Helena Antipoff inaugurou diversas instituições de apoio às crianças consideradas "anormais"” na época, além de se dedicar à formação de professores para Educação Especial (BORGES, 2015).

Pode-se considerar que desde essa época, comunidades epistêmicas foram se constituindo no país, preparando o terreno para que o movimento internacional de Educação Inclusiva pudesse se estabelecer no país.

As comunidades epistêmicas são muitas vezes pensadas como redes de especialistas (networks of knowledge-based experts) que, como tal, possuem e desenvolvem conhecimento relevante para as políticas públicas. Ademais, elas reivindicam ser ouvidas nos processos decisórios das políticas relativas às suas áreas de especialidade (FARIA, 2018, p.88).

Um dos exemplos importantes da influência das comunidades epistêmicas nas políticas de Educação Especial, diz respeito ao vocábulo "excepcional”: “A influência de Helena Antipoff na história da Educação Especial brasileira é tão significativa que o conceito de "excepcional" usado nas diretrizes do CENESP é o formulado por esta educadora" (BATISTA, 2019, p.71).Outros pesquisadores apontam a importância dos especialistas na formulação das políticas públicas de Educação Especial a partir dos anos 1930 (BORGES, 2019; RAFANTE, 2011, 2017; MAZOTTA, 2011).

No caso brasileiro, as iniciativas acerca da Educação Especial, a princípio isoladas em cada estado da federação, ganham força com a criação do CENESP (Centro Nacional de Educação Especial). Criado no ano de 1973, o Órgão Central de Direção Superior, teve a finalidade de expandir e melhorar o atendimento ao excepcional no Brasil. Com a criação do CENESP, a formação e aperfeiçoamento de pessoal docente e especialistas para atuação na Educação Especial passou a integrar o quadro de ações prioritárias deste órgão (BATISTA, 2019).

O contexto brasileiro, a partir dos anos 1960, favoreceu o fortalecimento do campo da Educação Especial que culminou na criação do CENESP. Além das comunidades epistêmicas, outros grupos passaram a reivindicar direitos:

Assim, o contexto histórico da década de 1960 apontava um avanço científico representado tanto pela comprovação das potencialidades educacionais dos portadores de deficiências quanto pelo criticismo científico direcionado aos serviços educacionais existentes. Paralelamente, ocorria a explosão da demanda por ensino especial ocasionada pela incorporação da clientela que, cada vez mais, passou a ser excluída das escolas comuns, fazendo crescer o mercado de empregos dos profissionais especializados e a consolidação da área, o que também ajudou na organização política de grupos que passaram a demandar por mudanças. Isso tudo, associado ao custo alarmante dos programas paralelos especializados que implicavam segregação, num contexto de crise econômica mundial, permitiu a aglutinação de interesses de políticos, prestadores de serviços, pesquisadores, pais 
e portadores de deficiências em direção à integração dos portadores de deficiências nos serviços regulares da comunidade (MENDES, 2006, p. 388).

Portanto, além das comunidades epistêmicas, movimentos sociais organizados tiveram uma forte influência na formulação de políticas públicas para essa população, a partir da década de 1970. Quanto à definição de movimentos sociais:

Os movimentos realizam diagnósticos sobre a realidade social, constroem propostas. Atuando em redes, constroem ações coletivas que agem como resistência à exclusão e lutam pela inclusão social. Constituem e desenvolvem o chamado empowerment de atores da sociedade civil organizada à medida que criam sujeitos sociais para essa atuação em rede. Tanto os movimentos sociais dos anos 1980 como os atuais têm construído representações simbólicas afirmativas por meio de discursos e práticas. Criam identidades para grupos antes dispersos e desorganizados, como bem acentuou Melucci (1996). Ao realizar essas ações, projetam em seus participantes sentimentos de pertencimento social. Aqueles que eram excluídos passam a se sentir incluídos em algum tipo de ação de um grupo ativo (GOHN, 2011, p. 336).

Desde a década de 1950, pais de crianças com deficiência se uniram em associações e criaram escolas especiais em todo o Brasil. As associações que mais cresceram foram a Sociedade Pestalozzi do Brasil e Associação de Pais e Amigos dos Excepcionais (APAE). Foi também a partir dessa década que se intensificaram as associações formadas por pessoas com deficiência. A primeira entidade nacional reconhecida foi o Conselho Brasileiro para o Bem-Estar dos Cegos (CBEC), fundado no Rio de Janeiro, em 1954, mas existem registros de associações de surdos a partir dos anos 1930 (LANNA JÚNIOR, 2010).

Não é possível discutir o movimento político das pessoas com deficiência sem trazer à tona a importância do modelo social da deficiência, iniciado no Reino Unido nos anos 1960. A frase "Nada sobre nós sem nós” se tornou o lema das pessoas com deficiência que passaram a exigir que fossem ouvidas, para que pudessem expressar suas reais necessidades. O modelo social desloca o foco da deficiência do corpo, para a interação entre o corpo e a sociedade. As pessoas com deficiência passam a protagonizar os movimentos em defesa de seus direitos.

A partir dos anos 1970, surgiram as primeiras organizações compostas e dirigidas por pessoas com deficiência, contrapondo-se às associações que prestavam serviços a este público, mas que não tinham em seus quadros, pessoas com deficiência (LANNA JÚNIOR, 2010)

Os novos movimentos sociais, dentre os quais o movimento político das pessoas com deficiência, saíram do anonimato e, na esteira da abertura política, uniram esforços, formaram novas organizações, articularam-se nacionalmente, criaram estratégias de luta para reivindicar igualdade de oportunidades e garantias de direitos (LANNA JÚNIOR, 2010, p.35). 
A Coalizão Pró-Federação Nacional de Entidades de Pessoas Deficientes foi criada em 1979, representando numa mesma associação, diferentes deficiências. A partir da década de 1980 as pessoas com deficiência ampliaram suas reivindicações para além das questões da educação: era necessário formular políticas de saúde, assistência, esporte, lazer, trabalho, etc.

Em 1988, a Constituição Federal reafirmou os direitos das pessoas com deficiência. Na década de 1990 iniciam-se as discussões sobre a Educação Inclusiva a partir das proposições internacionais, o que se consolida no Brasil em 2008, com a publicação da PNEEPEI. O contexto brasileiro se encontrava receptivo para efetuar as mudanças que os Organismos Internacionais propunham.

\section{Influência internacional e contexto local}

A discussão dos Organismos Internacionais, sobre a formação de professores para a Educação Especial e o papel das comunidades epistêmicas e movimentos sociais no processo que envolve o ciclo das políticas, permitiu perceber que o movimento que surge nos anos 1990 a favor da perspectiva da Educação Inclusiva, encontrou no Brasil um terreno fértil para que essas orientações pudessem ser implementadas.

Um dos pontos que merece destaque em relação à adoção da política de inclusão de alunos com deficiência no Brasil é a formação de professores. Segundo Oliveira (2019)

No documento da Organization for Economic Co-operation and Development (2005) é possível perceber como são amplas as expectativas e sérios os compromissos que deposita sobre os professores na atualidade, devendo estes responder de maneira eficaz às demandas dos alunos e ao mesmo tempo demonstrar sensibilidade em relação às questões culturais e de igualdade de gênero, e fomentar a tolerância. (OLIVEIRA, 2018, p. 53).

Souza e Pletsch (2017), em um estudo sobre a influência da ONU nas Políticas de Educação Inclusiva no país, discutiram principalmente documentos da Organização das Nações Unidas para a Educação e Cultura (UNESCO) e chegaram às seguintes conclusões: os documentos enfatizam que o professor é peça chave na construção de escolas inclusivas enfatizando a importância de se instrumentalizar os professores; para a formação de professores uma das estratégias mais indicada é a formação de multiplicadores e os cursos de Educação a Distância (EaD); é incentivada a formação de redes formadas por representantes de movimentos políticos, comunidade, profissionais de saúde. E concluem que muitas dessas práticas foram incorporadas ao contexto brasileiro, como por exemplo, o Programa Educação Inclusiva: Direito à Diversidade, que adotou um modelo de multiplicadores na formação de professores (SOUZA; PLETSCH, 2017).

Chama a atenção três aspectos relacionados à influência dos OI's no contexto local e a forma como a política foi adotada. Primeiro, a ênfase dada ao papel do professor. Sobre ele, recai a responsabilidade pelo sucesso escolar dos alunos. De acordo com a cúpula de 2014, 
eles precisam estar equipados com as habilidades necessárias para identificar alunos em dificuldades, entender as diferenças culturais e diagnosticar os alunos. No entanto, a formação continuada desses professores ocorre muitas vezes de forma precária através dos cursos EaD (modalidade que poderia ser utilizada como parte de um curso, mas que na maior parte das vezes é usada na totalidade da formação) ou na forma de multiplicadores, em que alguns professores são formados e retornam aos seus lugares de origem para disseminar o que aprenderam. No contexto brasileiro é possível perceber claramente a responsabilização dos professores. No entanto, como no Brasil existem os professores especialistas e os professores capacitados, a responsabilização maior pelos alunos PAEE incide sobre os especialistas, enquanto os professores regentes das salas de aula, se queixam do despreparo para lidar com esse público e da falta de capacitação. Esse é um dos principais impasses na escolarização dos alunos com deficiência, que passam a maior parte do tempo com os professores regentes e não com os especialistas.

Segundo, a própria definição de PAEE no contexto brasileiro. É importante destacar que essa definição foi construída gradativamente no contexto local. Nos anos 1930, os alunos eram nomeados como “anormais”. Alunos com deficiência, problemas comportamentais, e até mesmo crianças órfãs eram o público da educação especial. Nos anos 1950 os alunos com deficiência ocuparam as escolas especiais. Alunos com problemas comportamentais e de aprendizagem permaneceram nas classes especiais, nas escolas comuns. A partir dos anos 1990, delimita-se de forma mais clara no contexto brasileiro, quais os alunos seriam PAEE. Dessa forma, no Brasil, considera-se que a Educação Inclusiva é muito mais ampla e abrange todas as crianças que devem atingir o máximo de suas potencialidades no sistema educacional. Para isso, crianças com transtornos funcionais como Transtorno do Déficit de Atenção e Hiperatividade, ou Dislexia, por exemplo, tem direitos assegurados, como leitores que os auxiliem nas atividades avaliativas ou locais separados para a realização das mesmas. Mas a Educação especial, como modalidade, é uma prerrogativa dos alunos com Deficiência, Transtornos Globais do Desenvolvimento e Altas habilidades/Superdotação. A opção por essa definição do PAEE relaciona-se diretamente com a forma como se desenvolveu a Educação Especial no Brasil e como as comunidades epistêmicas locais influenciaram a concepção adotada.

Por fim, a noção de aprendizagem ao logo da vida. Essa abordagem, difundida por diferentes OI's, passou a fazer parte do ordenamento jurídico brasileiro através da Lei 13.632/2018. A nova lei, alterou a Lei de Diretrizes e Bases da Educação Nacional - LDB (Lei 9.394/1996), e incidiu diretamente nas modalidades da Educação de Jovens e Adultos (EJA) e na Educação Especial. No caso da EJA, a lei constitui-se como um instrumento para a educação ao longo da vida para quem não teve acesso aos estudos no tempo previsto. No caso da Educação Especial, o Estado deve garantir a Educação Especial na primeira infância (zero a seis anos) e em todos os níveis e modalidades de ensino, se estendendo para toda vida. Nesse último caso, ainda não é possível avaliar os impactos de tal política para o campo da Educação Especial, tendo em vista o tempo curto para tal análise. Essa abordagem encontra respaldo em movimentos sociais de pessoas com deficiência que reivindicam a possibilidade de terem assegurados seus direitos de educação ao longo da vida. 


\section{Considerações finais}

Os dados de matrículas de alunos PAEE em escolas regulares brasileiras, sob responsabilidade do INPE, são indicadores importantes no sentido de garantir informações quanto a efetivação das políticas educacionais de inclusão escolar no âmbito da Educação Especial. A análise desses dados evidencia que, quantitativamente, esses alunos têm tido acesso às escolas comuns, fato que pode ser entendido como sucesso dessas políticas. Nessa direção, nota-se que o país tem alcançado resultados no que diz respeito a garantia de acesso de alunos PAEE na escola comum, ou seja, há efeito das políticas educacionais implementadas com esse propósito.

No entanto, o país carece de políticas que garantam suporte para permanência e escolarização desses estudantes. Nos resultados apresentados no último relatório TALIS ${ }^{5}$, foi questionado aos professores brasileiros participantes quais áreas eles consideram prioritárias, caso houvesse um aumento de 5\% no investimento em educação. Dos respondentes, 88\% dos professores dos anos finais do ensino fundamental e $83 \%$ dos professores das escolas de ensino médio disseram que esse investimento deveria servir de "apoio aos alunos com necessidades especiais ${ }^{6 ”}$ (TALIS, 2019). Considerando que esses dados retratados dão suporte ao desenvolvimento de políticas educacionais, vê-se do ponto de vista dos próprios professores da educação básica a necessidade de garantir suporte à escolarização desses estudantes, identificada como uma demanda oportuna, uma vez que o acesso já tem sido garantido.

O que se nota é um aumento da responsabilização do professor mediante a demanda posta pela inclusão escolar, como exemplo o caráter multifuncional do professor da Educação Especial. Dessa forma, nota-se certa precarização do trabalho desse profissional à medida que se ampliam suas funções e pouco, ou nenhum respaldo do ponto de vista de formação é oferecido.

No momento atual foi lançada uma proposta de reformulação da política de 2008 (BRASIL, 2008), intitulada como "Política Nacional de Educação Especial: Equitativa, Inclusiva e ao longo da vida” (BRASIL, 2018). Pode-se notar no título da proposta certa convergência, por exemplo, à Declaração de Incheon, produto do Fórum Mundial da Educação que ocorreu no ano de 2015, liderado pela UNESCO, cujo foco foi definir prioridades e estratégias para a educação rumo à 2030.

A influência das OI’s nas políticas de Educação Especial no Brasil pode ser evidenciada na formação de professores e na formulação das políticas locais. Mas o contexto local se organiza de forma a adotar essas políticas, de maneira mais ou menos evidente. No Brasil, as comunidades epistêmicas locais já atuavam desde os anos 1930, na tentativa de garantir a educação para os alunos com deficiência. Os movimentos sociais, primeiro de famílias e depois das próprias pessoas com deficiência, também contribuíram para que a Educação Especial na perspectiva inclusiva pudesse se consolidar no país. 
Notas

1. São considerados PAEE alunos com deficiências, transtornos globais do desenvolvimento, altas habilidades/ superdotação (BRASIL, 2008).

2. Para maiores informações sobre as resoluções da ONU sobre as pessoas com deficiência, ver Madureira (2016).

3. A autoeficácia é um conceito criado pelo psicólogo Albert Bandura e pode ser definida como um julgamento que o indivíduo faz acerca de suas capacidades e habilidades para agir em um domínio específico estando na base da motivação, o bem-estar e as realizações pessoais futuras (Iaochite et al, 2016,)

4. Anormais: crianças que no início do século 20, além das deficiências, apresentavam problemas comportamentais, mentais e até mesmo as crianças órfãs e institucionalizadas.

5. A Pesquisa Internacional sobre Ensino e Aprendizagem (Talis), tradução de Teaching and Learning International Survey, é uma pesquisa internacional coordenada pela Organização para Cooperação e Desenvolvimento Econômico (OCDE). Seu foco é avaliar o ambiente de ensino e aprendizagem, e as condições de trabalho dos professores e diretores nas escolas. No Brasil, a aplicação e o tratamento dos dados é responsabilidade do Instituto Nacional de Estudos e Pesquisas Educacionais Anísio Teixeira (Inep). In: http://inep.gov.br/pesquisa-talis

6. Compreende-se que o termo Necessidades Especiais remete a uma parcela mais ampla de estudantes, no entanto, historicamente e politicamente no Brasil os estudantes do público-alvo da Educação Especial têm sido referenciados como os alunos com “necessidades especiais”.

\section{Referências bibliográficas}

ALMEIDA, M.; VIANA, J. Problematizações e preconizações internacionais sobre formação de professores. Relatório do Projeto Políticas públicas para a melhoria do ensino médio: socialização científica, tradução e transferência de resultados. Universidade de Lisboa, 2019, 52 p. Relatório.

ASIA SOCIETY (2014). Excellence, Equity, and Inclusiveness. High Quality Teaching for All. The 2014 International Summit on the Teaching Profession. Wellington, New Zealand: Asia Society. Disponível em: AsiaSociety.org/teachingsummit. Acesso em: 02/03/2019.

Anita Paes Barreto. Psicol. cienc. prof., Brasília, v. 20, n. 3, p. 49, Sept. 2000. Available from $<$ http://www.scielo.br/scielo.php?script=sci_arttext\&pid=S1414-

98932000000300009\&lng=en\&nrm=iso $>$. access $\quad$ on $26 \quad$ Fev. 2020. https://doi.org/10.1590/S1414-98932000000300009.

BATISTA, G. F. O centro nacional de educação especial e o atendimento aos "excepcionais”: antecedentes, atores e ações institucionais, Dissertação de Mestrado no Programa de PósGraduação em Educação, Contextos Contemporâneos e Demandas Populares, 2019.

BORGES, A. A. P. De anormais a excepcionais: História de um conceito e de práticas inovadoras em educação especial. Curitiba: CRV, 2015.

BORGES, A. A. P.; CAMPOS, R. H. de F. A Escolarização de Alunos com Deficiência em Minas Gerais: das Classes Especiais à Educação Inclusiva1. Revista brasileira de Educação Especial, v. 24, número especial, p. 69-84, 2018.

Constituição da República Federativa do Brasil. Brasília: Diário Oficial da República Federativa da União, 1988.

Portaria nº 1793 de 1994. Brasília: Ministério da Educação, 1994. 
Lei $\mathbf{n}^{0}$ 9.394. Lei de diretrizes e bases da educação nacional. Brasília: Ministério da Educação, 1996.

. Conselho Nacional de Educação. Resolução CNE/CEB n 2, de 11 de setembro de 2001. Institui diretrizes nacionais para a educação especial na educação básica. Brasília: Conselho Nacional de Educação, 2001a.

Presidência da República. Lei no 10.172, de 9 de janeiro de 2001. Aprova o Plano Nacional de Educação e dá outras providências. Brasília, DF, 2001b.

. Ministério da Educação. Diretrizes para a formação inicial de professores da educação básica. Brasília: Ministério da Educação, 2001c.

. Conselho Nacional de Educação. Resolução CNE/CP nº 1, de 15 de maio de 2006. Institui diretrizes curriculares nacionais para o curso de graduação em Pedagogia, licenciatura. Brasília: Conselho Nacional de Educação, 2006a.

. Ministério da Educação. Secretaria de Educação Especial. Programa Educação Inclusiva: direito à Diversidade. Brasília, DF, 2006b.

Programa de Implantação de Salas de Recursos Multifuncionais. MEC, SEESP, 2007a.

Decreto $n^{0}$ 6.094, de 24 de abril de 2007. Dispõe sobre a implementação do Plano de Metas Compromisso Todos pela Educação, pela União Federal, em regime de colaboração com Municípios, Distrito Federal e Estados, e a participação das famílias e da comunidade, mediante programas e ações de assistência técnica e financeira, visando a mobilização social pela melhoria da qualidade da educação básica. Brasília: Ministério da Educação, 2007b.

Política de educação especial na perspectiva da educação inclusiva. Brasília: Ministério da Educação, 2008.

Resolução no 4, de 2 de outubro de 2009. Institui Diretrizes Operacionais para o Atendimento Educacional Especializado na Educação Básica, modalidade Educação Especial. Brasília: Ministério da Educação, 2009.

Decreto $n^{0}$ 7.611, de 17 de novembro de 2011. Dispõe sobre a educação especial, o atendimento educacional especializado e dá outras providências. Brasília: Ministério da Educação, 2011.

. Presidência da República. Lei no 13.005, de 25 de junho de 2014. Aprova o Plano Nacional de Educação - PNE e dá outras providências. 2014. Brasília, DF, 2014.

. Resolução $\mathbf{n}^{0}$ 2, de $\mathbf{1}^{\circ}$ de Julho de 2015. Diretrizes Curriculares Nacionais para a formação inicial em nível superior e para a formação continuada, 2015.

Ministério da Educação. Política nacional de educação especial: equitativa, inclusiva e ao longo da vida. Brasília, DF: MEC, 2018.

Lei $n^{0}$ 13.632. Altera a Lei $n^{\circ}$ 9.394, de 20 de dezembro de 1996 (Lei de Diretrizes e Bases da Educação Nacional), para dispor sobre educação e aprendizagem ao longo da vida. Brasília, 2018

Resolução CNE/CP n 2, de 20 de dezembro de 2019. Define as Diretrizes Curriculares Nacionais para a Formação Inicial de Professores para a Educação Básica e institui a Base Nacional Comum para a Formação Inicial de Professores da Educação Básica (BNC-Formação). Brasília, DF: MEC, 2019. 
BUENO, J. S. Crianças com necessidades educativas especiais, política educacional e a formação de professores: generalistas ou especialistas? Revista Brasileira de Educação Especial, v. 3, n. 5, p. 7-26, 1999.

CARAMORI, P. M.; MENDES, E. G.; PICHARILLO, A. D. M. A formação inicial de professores de sala de recursos multifuncionais a partir do olhar dos professores atuantes. Revista de Educação PUC-Campinas, v. 23, p. 124-141, 2018.

CRUZ, G. C.; GLAT, R. Educação inclusiva: desafio, descuido e responsabilidade de cursos de licenciatura. Educar em Revista, n. 52, p. 257-273, 2014.

DELORS, J. et al. Educação: um tesouro a descobrir: relatório para a UNESCO da Comissão Internacional sobre Educação para o Século XXI. São Paulo: Cortez; Brasília, DF: UN ESCO, 1998.

FARIA, C. A. P. de. Políticas públicas e relações internacionais. - Brasília: Enap, 2018. 104 p.

GIROTO, C. R. M.; POKER, R. B.; OMOTE, S. As tecnologias nas práticas pedagógicas inclusivas. Marília. Oficina Universitária. São Paulo: cultura Acadêmica, 2012.

GOHN, M. G. Movimentos sociais na contemporaneidade. Revista Brasileira de Educação, v. 16, n. 47, p. 333-361, 2011.

IAOCHITE, Roberto Tadeu et al. Autoeficácia no campo educacional: revisão das publicações em periódicos brasileiros. Psicol. Esc. Educ., Maringá, v. 20, n. 1, p. 45-54, Apr. 2016. Available from $\quad<$ http://www.scielo.br/scielo.php?script=sci_arttext\&pid=S141385572016000100045\&lng=en\&nrm=iso $>$. access on 02 Feb. 2020. https://doi.org/10.1590/2175353920150201922.

INEP. Instituto Nacional de estudos e pesquisa educacionais Anísio Teixeira. Sinopse Estatística da Educação Básica 2017. Brasília: Inep 2018.

KASSAR, M. C. M. A formação de professores para a Educação inclusiva e os possíveis impactos na escolarização de Alunos com deficiências. Cadernos Cedes, Campinas, v. 34, n. 93, p. 207224, maio 2014.

Lanna Júnior, Mário Cléber Martins (Comp.). História do Movimento Político das Pessoas com Deficiência no Brasil - Brasília: Secretaria de Direitos Humanos. Secretaria Nacional de Promoção dos Direitos da Pessoa com Deficiência, 2010. 443p

MADRUGA, S. Pessoas com deficiência e direitos humanos: ótica da diferença e ações afirmativas. São Paulo: Saraiva, 2013. 367p.

MADUREIRA, A. R. V. Pessoa com deficiência na América do Sul: um estudo sobre as legislações brasileira, argentina e chilena, Dissertação de Mestrado em Relações Internacionais, PUCMINAS, 2018.

MAZZOTTA, M. J. S. Educação Especial no Brasil: História e políticas públicas. 6 ed. São Paulo: Cortez, 2011.

MENDES, E. G. A radicalização do sobre inclusão escolar no Brasil. Revista Brasileira de Educação, v. 11, n. 33, p. 387-405, 2006.

MENDES, E. G.; CABRAL, L. S. A.; D’AFFONSECA, S. M.; CALHEIROS, D. S. A formação dos professores especializados segundo os pesquisadores do Observatório Nacional de Educação Especial. Educação e Fronteiras On-Line, v.5, n.13, p.84-95, 2015. 
MENDES, E. G. Sobre alunos "incluídos" ou "da inclusão": Reflexões sobre o conceito de inclusão escolar. In VICTOR, S. L.; VIEIRA, A. B.; MARTINS, I. (Orgs.), Educação especial inclusiva: Conceituações, medicalização e políticas, p. 60-83. Campos dos Goytacazes, RJ: Brasil Multicultural, 2017.

MENDES, E. G.; ALMEIDA, M. A., CABRAL, L. S. A. Apresentação (Orgs.) In: MENDES, E. G.; ALMEIDA, M. A., CABRAL, L. S. A Perspectivas internacionais da educação especial e educação inclusiva. Marília: ABPEE, 2018.

OCDE. Organização para Cooperação e Desenvolvimento Econômico. Professores são importantes. Atraindo, desenvolvendo e retendo professores eficazes. São Paulo: Coedição Moderna: OCDE, 2006.

OCDE. Implementing Inclusive Education. Paris, 1997 Disponível em: https://files.eric.ed.gov/fulltext/ED413730.pdf Acesso em 04 jan. 2020

OLIVEIRA, D. A. A reestruturação da profissão docente no contexto da nova gestão pública na américa latina. Rev. FAEEBA - Ed. e Contemp., v. 27, n. 53, p. 43-59, 2018.

OLIVEIRA, D. A. A profissão docente no contexto da Nova Gestão Pública no Brasil. In: OLIVEIRA, D.A; CARAVALHO, L., M.; LEVASSEUR, L.; MIN, L.; NORMAND, R. (Orgs). Políticas Educacionais e a Estruturação da profissão do educador - perspectivas globais comparativas OLIVEIRA, D.A; CARAVALHO, L., M.; LEVASSEUR, L.; MIN, L.; NOREMAND, R. (Orgs). Petrópolis, RJ: Vozes, 2019. P. 271-300.

PEREIRA, R. S. A política de competências e habilidades na educação básica pública: relações entre Brasil e OCDE. Tese (Doutorado em Educação). Programa de Pós-graduação em Educação. Universidade de Brasília. 284f. 2016.

PLETSCH, D. A formação de professores para a educação inclusiva: legislação, diretrizes políticas e resultados de pesquisas. Educar em revista, n. 33, p. 143-156, 2009.

RAFANTE, H. C. Helena Antipoff, as Sociedades Pestalozzi e a Educação Especial no Brasil. 2011. 309p. Tese (Doutorado em Educação) - UFSCar, São Paulo, 2011.

RAFANTE, H.C. Política de Educação Especial no Brasil: a relação entre o Estado, a sociedade civil e as agências internacionais na criação do CENESP. In: Anais da $37^{\text {a }}$ Reunião Nacional da ANPEd. Florianópolis - UFSC: 2015, pp. 1-17. ISSN 2447-2808. Disponível em http://www.anped.org.br/sites/default/files/trabalho-gt15-3916.pdf. Acessado em agosto de 2017.

SOUZA, F. F.; PLETSCH, M. D. A relação entre as diretrizes do Sistema das Nações Unidas (ONU) e as políticas de Educação Inclusiva no Brasil. Ensaio: Avaliação e Políticas Públicas em Educação, v.25, n. 97, p. 831-853, 2017.

TALIS. Relatório Nacional pesquisa internacional sobre ensino e aprendizagem. Ministério da Educação - MEC. Instituto Nacional de Estudos e Pesquisas Educacionais Anísio Teixeira INEP. DIRETORIA DE ESTATÍSTICAS EDUCACIONAIS - DEED. Brasília/DF, 2019.

TORRES, J. P.; MENDES, E. G. Atitudes Sociais e Formação Inicial de Professores para a Educação Especial. Revista Brasileira de Educação Especial, v. 25, n. 4, p. 765-780, 2019.

UNESCO. Declaración Mundial sobre Educación para Todos y el Marco de Acción para Satisfacer las Necesidades Básicas de Aprendizaje. 1990. 
UNESCO. Declaração de Salamanca sobre Princípios, Políticas e Práticas na Área das Necessidades Educativas Especiais. In: Conferência Mundial sobre Necessidades Educativas: Acesso e Qualidade. Salamanca, Espanha: Unesco, 1994.

VAlladẽO, A. V. P.; ROCHA, T. C. C., BORGES, A. A. P. Política de cotas na Universidade Federal de Minas Gerais: uma análise do perfil dos alunos com deficiência. Revista Diálogos e Perspectivas em Educação Especial, v. 5, n. 1, p. 127-140, 2018.

VERGER, A. A política educacional global: conceitos e marcos teóricos chave. Práxis Educativa, v. 14, n. 1, p. 9-33, 2019.

WORLD BANK. Education for all: including children with disabilities.Washington, DC, 2003. Disponível em: <siteresources.worldbank.org/.../ EFAIncludingPortuguese.doc>. Acesso em: 20 jan. 2020

\section{Correspondência}

Adriana Araújo Pereira Borges: Professora de Políticas Públicas de Educação Especial e Inclusão na Faculdade de Educação (FaE) da UFMG. Professora da Pós-Graduação em Educação: Conhecimento e Inclusão Social, da FaE/UFMG. Possui graduação e mestrado em Psicologia e Doutorado em Educação. Membro da Associação Brasileira de Pesquisadores em Educação Especial. Membro do Gestrado Grupo de Estudos sobre Política Educacional e Trabalho Docente. Líder do LaPPEEI (Laboratório de Políticas e Práticas em Educação Especial e Inclusão, vinculado ao CNPQ). Tem experiência na área de Educação Especial e Políticas de Educação Especial e Inclusão, atuando principalmente nos seguintes temas: políticas de educação especial, transtorno do espectro do autismo, currículo para alunos com deficiência. Orienta projetos de mestrado e doutorado em História, Políticas e Práticas em Educação Especial e Inclusão.

E-mail: adriana.borges@terra.com.br

ORCID: 0000-0003-0493-0099

Josiane Pereira Torres: Docente na Faculdade de Educação (FaE), Departamento de Administração Escolar da Universidade Federal de Minas Gerais (UFMG). Doutora em Educação Especial pelo programa de Pós--graduação em Educação Especial da Universidade Federal de São Carlos (2018). Mestra (2013) em Educação Especial pelo Programa de Pós-graduação em Educação Especial da UFSCar. Licenciada em Física (2009) pela Universidade Estadual de Mato Grosso do Sul (UEMS). Desenvolve pesquisas nas áreas da inclusão escolar de estudantes do Público-alvo da Educação Especial e políticas públicas de formação de professores para a Educação Especial.

E-mail: jtfisica@gmail.com

ORCID: 0000-0002-1452-8223

Texto publicado em Currículo sem Fronteiras com autorização das autoras 